\title{
Bournemouth Boyun Anketi’nin Psikometrik Özelliklerinin İncelenmesi
}

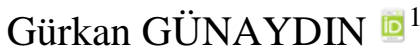

\section{ÖZ}

Amaç: Toplum genelinde sıklıkla görülebilen ve bireylerde kısıtlılık tablosu oluşturabilen boyun ağrısının, değerlendirilmesi ve takibinde son durum ölçeklerinin kullanımı büyük önem arz etmektedir. Hasta temelli bu ölçeklerden biri olarak karșımıza çıkan Bournemouth Boyun Anketi, boyun ağrılı hastalarda ağrı ve özrün yanı sıra biyopsikososyal özellikleri de değerlendirmektedir. Bu çalışmanın amacı Bournemouth Boyun Anketi'nin psikometrik özelliklerinin belirlenmesidir.

Gereç ve Yöntemler: Çalışmaya 73 boyun ağrılı birey dâhil olmuş ve analizler için katılımcılar Bournemouth Boyun Anketi ile birlikte Boyun Özür İndeksi, Boyun Ağrısı Özürlülük Skalası ve Kısa Form 36 anketlerini doldurmuşlardır. Otuz bir katılımcı ise test-tekrar test analizi için Bournemouth Boyun Anketi'ni 48 saat sonra tekrar tamamlamıştır.

Bulgular: Yapılan analizler sonucu anketin iç tutarlılık Cronbach alfa değerinin 0,853, test-tekrar test sınıf içi korelasyon katsayısı değerinin ise 0,932 olduğu bulunmuştur. Bu değerler anketin yüksek bir güvenirliğe sahip olduğuna işaret etmektedir. Gerçekleștirilen Pearson korelasyon analizi sonucunda Bournemouth Boyun Anketi'nin Boyun Özür İndeksi $(r=0,718)$ ve Boyun Ağrısı Özürlülük Skalası ( $(r=0,763)$ ile çok iyi düzeyde, Kısa Form 36'nın ilgili parametreleriyle $((-0,440)-(-0,594))$ ise iyi düzeyde ilişkili olduğu görülmüştür. Anketin bileşen sayısının belirlenmesi için yapılan açıklayıcı faktör analizi sonucu anketin tek faktörlü bir yapıya sahip olduğu bulunmuştur.

Sonuç: Bu çalı̧sma sonucunda Bournemouth Boyun Anketi'nin yeterli psikometrik özelliklere sahip olduğu ve boyun ağrılı hastalarda kullanımının uygun olduğu bulunmuştur.

Anahtar Kelimeler: Boyun ağrıs1; sağlık anketleri; faktör analizi.

\section{Investigation of Psychometric Properties of the Bournemouth Neck Questionnaire}

\begin{abstract}
Aim: The use of the outcome measurements in the evaluation and follow-up of neck pain, which can be seen frequently in society and create a table of limitations in individuals, is of great importance. The Bournemouth Neck Questionnaire, one of the patient-related questionnaires, evaluates pain and disability as well as biopsychosocial features in patients with neck pain. The aim of this study was to determine the psychometric characteristics of the Bournemouth Neck Questionnaire.

Materials and Methods: The study included 73 subjects with neck pain and for analyses participants filled Bournemouth Neck Questionnaire with Neck Disability Index, Neck Pain Disability Scale and Short Form 36. For testretest analysis 31 participants completed the Bournemouth Neck Questionnaire again after 48 hours.

Results: As a result of the analyses, the internal consistency Cronbach alpha value of the questionnaire was 0.853 and the test-retest intraclass correlation coefficient was 0.932 . These values indicate that the questionnaire has a high level of reliability. As a result of Pearson's correlation analysis, the Bournemouth Neck Questionnaire was very-good correlated with the Neck Disability Index $(\mathrm{r}=0.718)$ and Neck Pain Disability Scale $(\mathrm{r}=0.763)$ and good with the related parameters of Short Form $36((-0.440)-(-0.594))$. According to explanatory factor analysis conducted to determine the number of components of the questionnaire, it was found that the questionnaire had one factorial structure.
\end{abstract}

1 Aydın Adnan Menderes Üniversitesi, Sağlık Bilimleri Fakültesi, Fizyoterapi ve Rehabilitasyon Bölümü, Aydın, Türkiye 
Conclusion: In conclusion, it was found that Bournemouth Neck Questionnaire had sufficient psychometric features and appropriate to use for patients with neck pain.

Keywords: Neck pain; health surveys; factor analysis.

\section{GíRIS}

Boyun ağrısı; görülme sıklığındaki yükseklik ve oluşturduğu fonksiyonel bozukluk sebebiyle küresel bir sorun haline dönüşmüştür (1). Ülkemizde ayrıntılı bir çalışma olmamakla birlikte literatürdeki çalışmalar incelendiğinde Amerika Birleşik Devletlerinde nüfusun \%13,3'ünün (2), Avustralya'da \%30,2'sinin (3) ve İran'da ise \%30'unun (4) iş yaşantılarında kronik boyun ağrısı çektiği görülmektedir. Dünya genelinde engellilik halinin önde gelen nedenlerinden biri olmasına $(5,6)$ ve ağrı mekanizmalarının çoğunlukla benzer olduğu görülmesine rağmen (7) bel ağrisıyla mücadelede harcanan maddi kaynağın çok az bir kısmı boyun ağrıları için kullanılmaktadır $(6,7)$.

Boyun ağrıları temelde spesifik ve non-spesifik olarak sınıflandırılmaktadır. Spesifik olmayan boyun ağrıları travma, tümör veya herniasyon gibi belirli bir radyolojik kanıt olmadan oluşan basit boyun ağrısını ifade etmektedir (8). Bu tarz ağrıları değerlendirmek için klinisyenler çoğunlukla omurgada normal eklem hareketi ve kas kuvveti gibi ölçüm yöntemlerini kullanmaktadırlar (9). Ancak bu fizyolojik ölçümlerin semptomlarda azalma, günlük yaşam aktiviteleri ve çalışma hayatı gibi parametrelerle olan ilişkileri zayıf bulunmuştur $(10,11)$. $\mathrm{Bu}$ durum boyun ağrısı şikâyeti olan hastalarda omurganın objektif ve subjektif değerlendirmesinin hastaya uygun ve geçerliği yapılmış anketlerle gerçekleştirilmesi gerektiğini ortaya koymaktadır $(9,12)$. $\mathrm{Bu}$ sebeple boyun ağrılı hastaları değerlendirmek için hastalığa özgü birden fazla anket geliştirilmiştir. Boyun Ağrısı Özürlülük Skalası (13), Boyun Özür İndeksi (14) ve Kopenhag Boyun Fonksiyonel Özür Skalası (15) bunlardan birkaçı olarak karşımıza çıkmaktadır. Ancak boyun ağrısı için oluşturulan anketlerin çoğunlukla ağrı ve özrü değerlendirdiği ve boyun ağrısında etkilenebilecek bilişsel ve duyusal faktörlere yeteri kadar değinmediği ifade edilmektedir (16). Tüm bu veriler 1şığında Bolton ve Humpheys (17) 2002 yılında Bournemouth Bel Ağrısı Anketi'nden (18) revize edilen Bournemouth Boyun Anketi'ni geliştirmiştir. Bournemouth Boyun Anketi boyun ağr1lı hastalarda ağrı ve özrün yanında bilişsel ve duyusal faktörlerin de ölçüldüğü yedi soru ve toplam 70 puandan oluşan bir ankettir $(17,19)$.

Klinikte boyun ağrısını değerlendirmek için oluşturulan ve birbirine üstünlüğü bulunan çokça son durum ölçeği olmasına karşın, mevcut anketlerin hiçbirinin altın standart olarak kabul edilmediği akılda tutulmalıdır $(9,20)$. Bu yüzden boyun ağrısı ile ilişkili anketlerin çeşidinin ve farklı kültürlerdeki dil uyumlarının sayısının arttırılması, hastaların değerlendirilmesi ve takibinde klinisyenler ve araştırmacılar için fayda sağlayacaktır. Literatür incelendiğinde Bournemouth Boyun Anketi'nin Türkçe dil uyumunun Yılmaz ve arkadaşları tarafından gerçekleştirildiği görülmektedir (19). Ancak çalışmada yer alan vaka popülasyonu sadece kronik boyun ağrılı bireyleri kapsamaktadır. Anketin geçerlik ve güvenirliğinin ağrı süresi sınırlaması olmadan gerçekleştirilmesinin klinisyen ve araştırmacılara daha geniş bir perspektif sağlayacağı düşünülmektedir. Bu sebeple bu çalışmanın amacı boyun ağrılı bireylerde (akut, subakut, kronik) Bournemouth Boyun Anketi'nin psikometrik özelliklerinin belirlenmesidir.

\section{GEREÇ VE YÖNTEMLER}

$\mathrm{Bu}$ çalışma için Aydın Adnan Menderes Üniversitesi Sağlık Bilimleri Fakültesi Girişimsel Olmayan Klinik Araştırmalar Etik Kurulu'ndan 92340882-050.04.04 Sayı ve 2019/001 Protokol numarasıyla gerekli izin alınmış ve çalışmanın her aşamasında Helsinki Bildirgesi'nde tanımlanan ilkelere uyulmuştur.

\section{Hasta Popülasyonu}

Bu çalışma Şubat 2019-Haziran 2019 tarihleri arasında Aydın Adnan Menderes Üniversitesi'nde boyun ağrısı şikâyeti bulunan katılımcılar ile gerçekleştirilmiştir. Çalışma öncesi tüm katılımcılar çalışma hakkında bilgilendirilmiş ve yazılı izinleri alınmıştır. Bu bilimsel araştırmaya boyun ağrısı şikâyeti olan 18 yaşın üzerindeki ve Türkçe konuşup okuyabilen bireyler dâhil edilirken, hamile olan, boyun bölgesinden cerrahi ve travma geçiren, nörolojik ve sistemik rahatsızlığı olan (romatolojik hastalıklar, tümör, böbrek yetmezliği, akciğer hastalıkları vb.) katılımcılar çalışma dışında tutulmuştur. Örneklem genişliği her bir soru sayısı $(n=7)$ için en az on katılımcı alınması yöntemine göre gerçekleştirilmiştir $(21,22)$. Çalışma süresince 83 kişiye ulaşılmıştır. Altı katılımcı kendisinden doldurması istenen anketleri tamamlayamamış, iki katılımcı dâhil edilme kriterlerini karşılayamamış ve yine iki katılımcı ise çalışmaya katılmayı reddetmiştir. Sonuç olarak 73 kişi ile çalışma tamamlanmış ve her bir soru için en az 10 katılımcıya ulaşılabilmiştir.

\section{Hasta Temelli Anketler}

$\mathrm{Bu}$ bilimsel araştırmaya katılan tüm katılımcılar aşağıda ayrıntıları açıklanan Bournemouth Boyun Anketi, Boyun Özür İndeksi, Boyun Ağrısı Özürlülük Skalası ve Kısa Form 36 anketlerini sırasıyla doldurmuşlardır. Katılımcıların bu 4 anketi doldurma süresi yaklaşık olarak 10-15 dakika arasında zaman almıştır.

\section{Bournemouth Boyun Anketi}

Bu çalışmada Türkçe versiyonu kullanılan Bournemouth Boyun Anketi (19) Bolton ve arkadaşları (17) tarafından 2002 yılında Bournemouth Bel Ağrısı Anketi'nden revize edilerek oluşturulmuştur. Bournemouth Boyun Anketi ağrı yoğunluğu, günlük sosyal-fonksiyonel düzey, kayg1depresyon düzeyi, korku-kaçınma inanışının bilişsel ve davranışsal yönü ve ağrıyla baş edebilmenin sorgulandığı bir ankettir. Bournemouth Boyun Anketi yedi sorudan oluşmakta ve verilen cevaplar sıfır ile 10 arasında değişen sayısal analog skalasıyla puanlanmaktadır. Anketten alınabilecek maksimum puan 70'dir ve yüksek puan yüksek özre işaret etmektedir (17).

\section{Boyun Özür İndeksi}

Boyun Özür İndeksi ağrı yoğunluğu, kişisel bakım, ağırlık kaldırma, okuma, baş ağrıları, konsantrasyon, iş yaşamı, araba kullanımı, uyku ve boş zaman aktiviteleri olmak üzere 10 bölümden oluşmaktadır. Her bölüm, sıfır (pozitif durum) ile beş puan (negatif durum) arasında değişen bir değere sahiptir. Boyun Özür İndeksinde 
toplam puan sıfır ile 50 arasında değişmekte ve yüksek puan yüksek özre karşılık gelmektedir $(14,23)$.

\section{Boyun Ăgrısı Özürlülük Skalası}

Boyun ağrısı özürlülük skalası, ağrının oluşturduğu problemleri değerlendiren 20 soruluk bir ankettir. Her maddenin sıfır (ağrı veya aktivite sınırlaması yok) ile beş (mümkün olduğunca fazla ağrı veya maksimum sınırlama) arasında değişen bir puanı vardır. Toplam puan sıfır ile 100 arasında değişmektedir ve daha yüksek puan daha büyük bir özre işaret etmektedir $(13,24)$.

\section{Kısa Form 36}

Kısa Form 36 anketi, 36 madde ve sekiz alt ölçekten oluşan hasta temelli bir ankettir. Anketin alt ölçekleri fiziksel fonksiyon, sosyal fonksiyon, fiziksel sorunlara bağlı rol kısıtlamaları, bedensel ağrı, genel sağlık algısı, canlılık, duygusal problemler ve duygusal problemler nedeniyle rol kısıtlamalarını kapsamaktadır. Her alt ölçeğin skoru sıfır ile 100 arasında değişmektedir ve daha yüksek puanlar daha iyi duruma işaret etmektedir $(25,26)$.

\section{İstatistiksel Analiz}

$\mathrm{Bu}$ çalışma için tüm istatistiksel analizler SPSS 21.0 paket programı ve MVNtr çok değişkenli normallik web uygulaması ile gerçekleştirilmiştir (27). Bournemouth Boyun Anketi'nin psikometrik özelliklerinin belirlenmesi için öncelikle iç tutarlılık ve test-tekrar test analizleri yapılmış ve ardından anketin tavan-taban etkisi incelenmiştir. İç tutarlılık analizi (Cronbach alfa) için 0,80 ve üzeri uygun kabul edilmiştir $(28,29)$. Test-tekrar test analizi (sınıf içi korelasyon katsayısı) için 0,75 ve üzeri anlamlı sayılmış (30) ve analiz için 2 günlük süre aralığı tercih edilmiştir (31). Tavan-taban etkisi için ise \%15-\%20'ye kadar olan değerler normal kabul edilmiştir $(32,33)$. $\mathrm{Bu}$ analizler tamamlandiktan sonra anketin faktöriyel yapısı açıklayıcı faktör analizi ile sorgulanmıştır. Faktör analizi uygulanmadan önce varsayımları çok değişkenli normallik ve çoklu bağlantı yöntemleriyle kontrol edilmiştir. Çok değişkenli normallik için Mardia normallik testi, çoklu bağlantı için ise Varyans Inflasyon Faktör değerlendirilmiştir (22). Ayrica verilerin faktör analizine uygunluğu ve yeterliği Barlett küresellik ve Kaiser Meyer Olkin testleriyle ölçülmüştür. Anketin geçerliğinin belirlenebilmesi için ise Bournemouth Boyun Anketi'nin diğer anketlerle olan ilişkisine bakılmıştır. Bu analiz için Pearson korelasyon katsayısı kullanılmış ve korelasyonun gücü $r=0,81-1,00$ arası 'mükemmel', r=0,61-0,80 arası 'çok iyi', r=0,410,60 arası 'iyi', $r=0,21-0,40$ arası 'zayıf' ve $r=0-0,20$ arası ise çok zayıf veya anlamsız ilişki olarak yorumlanmıştır (34). Tüm istatistiksel analizler için $\mathrm{p}<0,05$ anlamlı kabul edilmiştir.

\section{BULGULAR}

Çalışmaya katılan 73 hastanın ayrıntılı demografik bilgileri Tablo 1'de özetlenmiştir. Yapılan analizler sonrası Bournemouth Boyun Anketi'nin Cronbach alfa değeri 0,853 bulunmuştur. Bu değer anketin yüksek bir iç tutarlılığa sahip olduğunu göstermektedir. Ayrıca anket sorularının iç tutarlılığa katkısını değerlendirmek için her bir soru çıkartılarak analiz tekrar edilmiştir. Yedinci soru haricinde sorular çıkarıldığında anketin iç tutarlılığının düştüğü ve dolayısıyla bu soruların anketin iç tutarlılığına katkı sağladığı görülmektedir (Tablo 2).
Tablo 1. Demografik özellikler

\begin{tabular}{|l|l|c|}
\hline Yaş (yıl)* & & $27,78 \pm 10,56$ \\
\hline Boy (cm)* & & $166,26 \pm 7,07$ \\
\hline Kilo (kg)* & & $64,82 \pm 11,91$ \\
\hline \multirow{2}{*}{ Boyun Ağrı Süresi (ay)* } & & $34,08 \pm 47,29$ \\
\hline \multirow{2}{*}{ Cinsiyet (n) (\%) } & Kadın & $59(80,8)$ \\
\cline { 2 - 3 } & Erkek & $14(19,2)$ \\
\hline \multirow{2}{*}{$\begin{array}{l}\text { Eğitim seviyesi } \\
(\text { n) (\%) }\end{array}$} & İlkokul & $1(1,4)$ \\
\cline { 2 - 3 } & Lise & $45(61,6)$ \\
\cline { 2 - 3 } $\begin{array}{l}\text { Sigara Kullanımı } \\
\text { (n) (\%) }\end{array}$ & Üniversite & $27(37,0)$ \\
\cline { 2 - 3 } & Evet & $24(32,9)$ \\
\hline
\end{tabular}

* Ortalama \pm Standart Sapma

Tablo 2. Bournemouth Boyun Anketi'nin iç tutarlılığ1

\begin{tabular}{|c|c|}
\hline & Cronbach alfa \\
\hline 1. Soru çıkarıldığında & 0,841 \\
\hline 2. Soru çıkarıldığında & 0,823 \\
\hline 3. Soru çıkarıldığında & 0,817 \\
\hline 4. Soru çıkarıldığında & 0,815 \\
\hline 5. Soru çıkarıldığında & 0,837 \\
\hline 6. Soru çıkarıldığında & 0,828 \\
\hline 7. Soru çıkarıldığında & 0,863 \\
\hline Toplam & 0,853 \\
\hline
\end{tabular}

Tablo 3. Bournemouth Boyun Anketi'nin test-tekrar test ve tavan taban etkisi

\begin{tabular}{|c|c|c|c|}
\hline $\begin{array}{c}\text { Bournemouth } \\
\text { Boyun Anketi }\end{array}$ & $\begin{array}{c}\text { Sinıf içi Korelasyon } \\
\text { Katsayıs1 } \\
(\% 95 \text { Güven Aralığı) } \\
(\text { Alt-Üst Sinır) }\end{array}$ & $\begin{array}{c}\text { Taban } \\
\text { Etkisi } \\
(\%)\end{array}$ & $\begin{array}{c}\text { Tavan } \\
\text { Etkisi } \\
(\%)\end{array}$ \\
\hline 1. soru & $\begin{array}{c}0,863 \\
(0,716-0,934)\end{array}$ & 1,4 & 0 \\
\hline 2. soru & $\begin{array}{c}0,911 \\
(0,814-0,957)\end{array}$ & 0 & 6,8 \\
\hline 3. soru & $\begin{array}{c}0,904 \\
(0,801-0,954)\end{array}$ & 0 & 26,0 \\
\hline 4. soru & $\begin{array}{c}0,790 \\
(0,564-0,899)\end{array}$ & 4,1 & 2,7 \\
\hline 5. soru & $\begin{array}{c}0,815 \\
(0,616-0,911)\end{array}$ & 4,1 & 2,7 \\
\hline 6. soru & $\begin{array}{c}0,873 \\
(0,737-0,939)\end{array}$ & 2,7 & 2,7 \\
\hline 7. soru & $\begin{array}{c}0,826 \\
(0,640-0,916)\end{array}$ & 2,7 & 2,7 \\
\hline Toplam puan & $\begin{array}{c}0,932 \\
(0,860-0,967)\end{array}$ & 0 & 0 \\
\hline
\end{tabular}

Anketin zamana göre değişmezliğini belirlemek için testtekrar test analizi gerçekleştirilmiş ve 31 vaka Bournemouth Boyun Anketi'ni 48 saat sonra tekrar tamamlamıştır. Yapılan analizler sonucu anketin her bir sorusunun (sınıf içi korelasyon katsayısı=0,790-0,911) ve toplam puanının (sınıf içi korelasyon katsayısı=0,932) zamana göre değişmezliğinin yüksek olduğu görülmüştür (Tablo 3). Tavan-taban etkisi ölçümünde ise ankette bir soru haricinde kabul edilebilir değerlere rastlanmıştır. Soysal fonksiyonların sorgulandığı üçüncü soruda görülen tavan etkisinin de (\%26) ters etki yapacak düzeyde (\%70) (35) olmadığı bulunmuştur (Tablo 3). 
Tablo 4. Faktör analizi sonuçları

\begin{tabular}{|c|c|c|c|c|c|c|}
\hline Faktör & \multicolumn{3}{|c|}{ Başlangıç Öz değerleri } & \multicolumn{3}{c|}{ Toplam Faktör Yükleri } \\
\hline & Toplam & $\begin{array}{c}\text { Varyans } \\
\%\end{array}$ & $\begin{array}{c}\text { Yığılımlı } \\
\%\end{array}$ & Toplam & $\begin{array}{c}\text { Varyans } \\
\%\end{array}$ & $\begin{array}{c}\text { Yığılımlı } \\
\%\end{array}$ \\
\hline 1 & 3,781 & 54,019 & 54,019 & 3,781 & 54,019 & 54,019 \\
\hline 2 & 0,937 & 13,379 & 67,398 & & & \\
\hline 3 & 0,836 & 11,938 & 79,336 & & & \\
\hline 4 & 0,443 & 6,335 & 85,671 & & & \\
\hline 5 & 0,442 & 6,313 & 91,984 & & & \\
\hline 6 & 0,344 & 4,909 & 96,893 & & & \\
\hline 7 & 0,217 & 3,107 & 100,000 & & & \\
\hline
\end{tabular}

Anketin faktör yükünün belirlenmesi için öncelikle Mardia normallik testi gerçekleştirilmiş ve çok değişkenli normalliğin sağlandığ görülmüştür $(p>0,05)$. Daha sonra gerçekleştirilen Varyans Inflasyon Faktör ise çoklu bağlantının görülmediğine işaret etmektedir $(<4,000)$ (36). Vakaların faktör analizine uygunluğu ve yeterliği Kaiser Meyer Olkin ve Bartlett küresellik testleriyle ölçülmüş ve çalışmaya katılan vakaların yeterli (Kaiser Meyer Olkin ölçüsü=0,823) ve uygun (Bartlett Ki kare testi=216,040; $\mathrm{p}<0,001)$ olduğu bulunmuştur. Yapılan açıklayıcı faktör analizi sonucu anketin tek faktörlü bir yapıya sahip olduğu Scree Plot (Yamaç Birikinti) grafiği ile gösterilmiştir (Şekil 1). Bournemouth Boyun Ağrısı Anketi'nin tek faktörü toplam varyansın \%54,019'unu oluşturmaktadır (Tablo 4) ve anketin faktör yükleri Tablo 5'te belirtilmektedir.

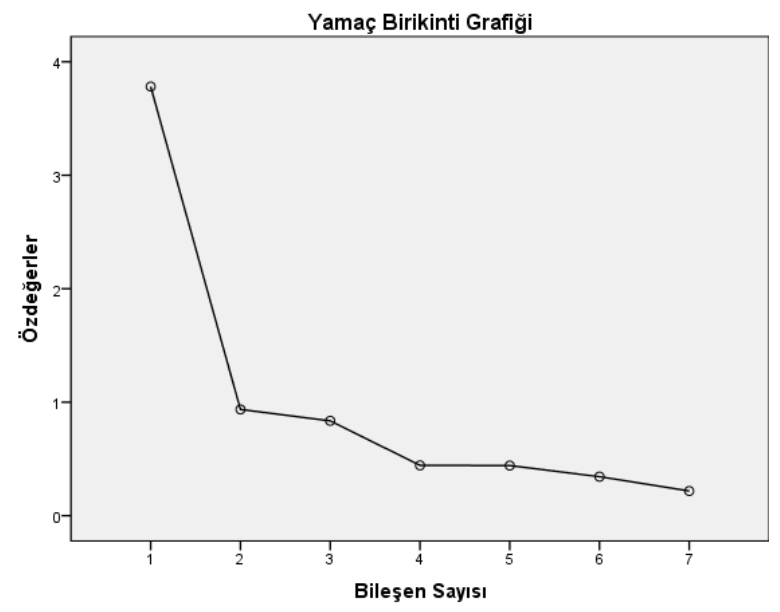

Şekil 1. Yamaç birikinti grafiği

Tablo 5. Bournemouth Boyun Anketi'nin faktör yükleri

\begin{tabular}{|c|c|}
\hline Bournemouth Boyun Anketi & Faktör yükü \\
\hline 1. Soru & 0,680 \\
\hline 2. Soru & 0,797 \\
\hline 3. Soru & 0,814 \\
\hline 4. Soru & 0,826 \\
\hline 5. Soru & 0,713 \\
\hline 6. Soru & 0,755 \\
\hline 7. Soru & 0,509 \\
\hline
\end{tabular}

Anketin geçerliğinin belirlenmesi için yapılan Pearson korelasyon analizi sonucu anketin toplam puanının, Boyun Özür İndeksi ve Boyun Ağrısı Özürlülük Skalası ile çok iyi derecede, Kısa Form 36 anketinin fiziksel fonksiyon, sosyal fonksiyon ve vücut ağrisı alt parametreleriyle ise iyi düzeyde ilişkili olduğu bulunmuştur (Tablo 6).

Tablo 6. Pearson korelasyon analizi sonuçları

\begin{tabular}{|c|c|c|}
\hline & \multicolumn{2}{|c|}{$\begin{array}{c}\text { Bournemouth Boyun } \\
\text { Anketi }\end{array}$} \\
\hline & $\mathrm{r}$ & $\mathrm{p}$ \\
\hline Boyun Özür İndeksi & 0,718 & $<0,001$ \\
\hline Boyun Ağrısı Özürlülük Skalası & 0,763 & $<0,001$ \\
\hline Kisa Form 36 fiziksel fonksiyon & $-0,440$ & $<0,001$ \\
\hline Kisa Form 36 sosyal fonksiyon & $-0,547$ & $<0,001$ \\
\hline Kısa Form 36 vücut ağrıs1 & $-0,594$ & $<0,001$ \\
\hline
\end{tabular}

$\mathrm{Bu}$ çalışma ile Bournemouth Boyun Anketi $(31,86 \pm 12,05)$, Boyun Özür İndeksi $(12,76 \pm 5,16)$ ve Boyun Ağrısı Özürlülük Skalası'nın $(35,78 \pm 17,37)$ ortalama puan değerleri hesaplanmıştır. Anketlerden alınabilecek maksimum puanlara göre ortalamalar değerlendirildiğinde, Bournemouth Boyun Anketi'nin toplam puana göre yüzde \%45,51, Boyun Özür İndeksi'nin \%28,35 ve Boyun Ağrıs1 Özürlülük Skalası'nın ise \%37,66'lık bir değere sahip olduğu görülmektedir. Bu analize göre Bournemouth Boyun Anketi'nin puan yüzdesi diğer iki son durum ölçeğine göre daha orta düzeyde konumlanmaktadır.

\section{TARTIŞMA}

Bournemouth Boyun Anketi'nin psikometrik özelliklerinin incelenmesi amacıyla gerçekleştirilen bu araştırma sonucunda, anketin Türk dil uyumunun boyun ağrılı hastaların kullanımı için uygun olduğu görülmüştür.

Boyun ağrısının toplumdaki görülme sıklığı ve etkisi düşünüldüğünde (1) yarattığı fonksiyonel bozukluğun ortadan kaldırılması için yapılması gerekenler klinisyenlerin çoğunlukla ilgisini çekmektedir. Kas iskelet sistemi ağrılarında doğru bir tedavi yaklaşımının ve takibinin sergilenebilmesi için hastaya ve hastalığa uygun son durum ölçeklerinin kullanımı büyük önem arz etmektedir (19,37). Ancak asıl problem hangi anketin hangi durumlarda kullanılması gerektiğidir. Yapılan çalışmalar boyun ağrılı hastalarda kullanılan son durum ölçeklerinin hiçbirinin altın standart olarak kabul edilmediğini göstermektedir $(9,20)$. Bu sebeple boyun ağrılı hastalarda kullanılan anket sayısının arttırılması ve bu anketlerin pozitif ve negatif özelliklerinin ortaya 
çıkarılabilmesi araştırmacı ve klinisyenlere fayda sağlayacaktır. İşlevsellik, yetiyitimi ve sağlığın uluslararası sınıflandırması (ICF) hasta temelli son durum ölçeklerini araştıran en iyi sınıflama sistemidir $(38,39)$. $\mathrm{Bu}$ sınıflama modeline göre karmaşık bir etiyopatogenez olan boyun ağrısı için biyopsikososyal yaklaşım elzem olarak gösterilmektedir $(38,40)$. Bournemouth Boyun Anketi'nin, kısa zamanda doldurulması, kolay ve anlaşılır yapısı, basit puanlaması $(1,37)$ ve boyun ağrılı hastaları ağr1 ve özrün yanı sıra biyopsikososyal temelde de değerlendirmesi $(1,17,39)$, onu diğer anketlerden pozitif yönde ayrıştırmaktadır.

Yapılan analizler sonucunda anketin iç tutarlılık değerinin 0,853 olduğu bulunmuştur. İç tutarlılık değeri orijinal versiyonunda 0,87 (17), kronik boyun ağrılarında gerçekleştirilen Türkçe versiyonunda 0,877 (19), İtalyan versiyonunda 0,89 (39), Alman versiyonunda 0,80 (37) ve Çin versiyonunda ise 0,89 (1) olarak bulunmuştur. Sonuçlar karşılaştırıldığında anketin diğer dil uyumlarına benzer şekilde yüksek bir iç tutarlılığa sahip olduğu görülmektedir.

Literatürde test-tekrar test analizinin gerçekleştirilmesi için kullanılacak süre konusunda bir uzlaşı bulunmamaktadır (31). Çok kısa test-tekrar test süresinin verilen cevapların hatırlanmasına yol açacağı, uzun sürelerin de hastanın klinik tablosunda bir farklılık oluşturabilmesi nedeniyle sonuçların yanlış yorumlanacağı ifade edilmektedir $(41,42)$. Bu sebeple bu çalışmada test-tekrar test süresinin belirlenmesi için Marx ve arkadaşlarının (31) çalışmalarından yola çıkılmış ve iki günlük aralık belirlenmiştir. $\mathrm{Bu}$ çalışma sonucu anketin toplam puan sınıf içi korelasyon katsayısı değeri 0,932 bulunmuştur. $\mathrm{Bu}$ değer orijinal versiyonda 0,65 (17), Alman versiyonunda 0,99 (37), Çin versiyonunda 0,97 (1), Yılmaz ve arkadaşlarının çalışmasında ise 0,945 (19) olarak gösterilmiştir. Sonuçlar kıyaslandığında diğer dil uyumlarının orijinal versiyona göre daha yüksek sınıf içi korelasyon katsayısı değerlerine sahip olduğunu göstermektedir. $\mathrm{Bu}$ sonuçlar anketin zamana göre değişmezliğini desteklemektedir.

Tavan-taban etkisi anketlerin psikometrik özelliklerinin karşılaştırılmasında önemli bir basamaktır. Tavan-taban etkisinin hesaplanmasıyla birlikte anketin klinik durum değişikliklerine ne kadar hassas olduğu belirlenebilmektedir (35). Bu çalışmada gerçekleştirilen analiz sonucu ankette bir soru haricinde tavan-taban etkisiyle karşılaşılmadığı üçüncü soruda görülen tavan etkisinin de olumsuz etki yapacak düzeyde olmadığ görülmüştür. Diğer dil uyumları incelendiğinde de tavantaban etkisiyle karşılaşılmamıştır $(1,39,43)$.

Yapılan analizler sonucunda son durum ölçeklerinin ortalama puan değerleri ve bu değerlerin anketlerdeki yüzdeleri hesaplanmıştır. Bulunan sonuçlara göre Bournemouth Boyun Anketi’nin \%45,51, Boyun Özür İndeksi'nin \%28,35 ve Boyun Ağrısı Özürlülük Skalasının ise \%37,66'lık bir puan yüzdesine sahip olduğu kaydedilmiştir. $\mathrm{Bu}$ değerler incelendiğinde Bournemouth Boyun Anketi'nden alınan ortalama puanların yüzdelik orana göre orta düzeyde konumlandığ ve bu durumun anketin boyun ağrılı hastaların takibinde klinik değişikliklerinin daha net gözlemlenebileceğini göstermektedir. Diğer iki anket incelendiğinde ise ortalama puan yüzdelerinin daha düşük olduğu ve vaka değerlendirme ve takibinde tavan-taban etkisine maruz kalma ihtimallerinin daha yüksek olduğu görülmektedir. Anketin Alman dil uyumu da bu durumu teyit etmektedir (37). Yılmaz ve arkadaşlarının kronik boyun ağrılı bireylerde Bournemouth Boyun Anketi’nin Türkçe versiyon geçerlik ve güvenirliğini inceledikleri çalışmada anketin tavan-taban etkisi ve ortalama puan yüzde dağılımları ile ilgili bir analiz paylaşmadığı görülmektedir (19). Gerçekleştirilen bu çalışmanın bu yönüyle de literatüre katkı sağlayacağı düşünülmektedir.

Bournemouth Boyun Anketi'nin bileşen yapısının belirlenmesi için gerçekleştirilen açıklayıcı faktör analizi sonrası anketin tek faktörlü bir yapıya sahip olduğu görülmüştür. Anketin İtalyan versiyonunda yapılan faktör analizi anketin iki bileşene sahip olduğunu belirtmektedir (39). Yılmaz ve arkadaşlarının çalışmalarında ise bu çalışmaya benzer şekilde tek faktörlü bir sonuçla karşıllaşılmıştır. Ancak Yılmaz ve arkadaşları çalışmalarında anketin faktör yapısının belirlenmesi için doğrulayıcı faktör analizi yöntemini kullanmışlardır (19). Bu sebeple tek faktörlü bir yapıyla karşılaşmış olmaları muhtemel gözükmektedir.

Bournemouth Boyun anketinin çok boyutlu bir son durum ölçeği olduğu varsayıldığında anketin birden fazla bileşen yapısının olması olağandır. Temel olarak anketlerin faktör analizinde bulunan öz değer yüklerinin bir ve üstü olması yeni bileşenleri ortaya çıkarmaktadır (39). Bu çalışma sonucunda tek faktörün altında bulunan öz değer yükü, 0,937 gibi bir değerle sınırda bulunmaktadır. $\mathrm{Bu}$ analizleri daha iyi yorumlayabilmek için parametrelerin faktör yükleri önem kazanmaktadır. Yapılan analiz sonucu 'ağrıyla baş edebilme' parametresinin diğer parametrelere göre daha düşük seviyede faktör yükü olduğu gözükmektedir (0,509). 'Ağrıyla baş edebilme' sorusunun benzer şekilde Cronbach alfa değerinin de diğer parametrelere göre daha düşük bulunduğu hesaba katıldığında sınırda bulunan bileşenin 'ağrıyla baş edebilme parametresi' olabileceği düşünülmektedir. Ancak versiyonlar arasındaki faktör farkının nerden kaynaklandığının belirlenmesi için farklı kültürlerde yapılacak yeni çalışmalara ihtiyaç vardır.

Birleşim geçerliği için yapılan analiz sonucu Bournemouth Boyun Anketi’nin Boyun Özür İndeksi ve Boyun Ağrısı Özürlülük Skalası ile çok iyi düzeyde, Kısa Form 36'nın ilgili parametreleriyle ise iyi düzeyde ilişkili olduğu bulunmuştur. Orijinal versiyonunun Boyun Özür İndeksi $(0,51)$ ve Boyun Ağrısı Özürlülük Skalası $(0,63)$ ile iyi seviyede ilişkisi olduğu belirtilmiştir (17). Çin versiyonunda Boyun Özür İndeksi $(0,82)$ ve K1sa Form 36'nın ilgili parametreleriyle yeterli düzeyde ilişkili olduğu gösterilmiştir (1). İtalyan versiyonunda Boyun Ağrısı Özürlülük Skalası $(0,67)$ ve EuroQol'un ilgili parametreleriyle iyi düzeyde ilişkiye sahip olduğu belirtilmiştir (39). Yılmaz ve arkadaşlarının çalışmalarında ise Boyun Ağrısı Özürlülük Skalası $(0,76)$ ve Boyun Özür İndeksi $(0,72)$ ile güçlü ilişki görüldüğü ifade edilmiştir (19). Bu değerler anketin geçerliğini desteklemektedir.

$\mathrm{Bu}$ çalışmanın bazı limitasyonları bulunmaktadır. Bournemouth Boyun Anketi'nin klinik değişikliklere duyarlılığın belirlenmesinde önemli bir ölçüt olan tepkisellik analizi gerçekleştirilememiştir. Boyun ağrılı hasta gruplarının belirlenen standart tedavi programı 
öncesi ve sonrasında Bournemouth Boyun Anketi ile değerlendirilmesi tepkiselliğin belirlenmesinde yardımcı olacaktır.

\section{SONUÇ}

Çalışma sonucu anketin yeterli düzeyde psikometrik özelliklere sahip olduğu bulunmuştur. Bournemouth Boyun Anketi kısa sürede tamamlanması, kolay uygulanabilmesi ve çok boyutlu bir son durum ölçeği olması sebebiyle boyun ağrılı hastaların değerlendirilmesinde tercih edilebilir.

\section{KAYNAKLAR}

1. Zhang ZC, Jia ZY, Cheng YJ, Wang F, Yang YL, Li $\mathrm{M}$, et al. Cross-cultural adaptation and validation of the Simplified-Chinese version of neck bournemouth questionnaire for patients in mainland China. Spine. 2019; 44(7): E438-44.

2. Yang H, Haldeman S, Nakata A, Choi B, Delp L, Baker D. Work-related risk factors for neck pain in the US working population. Spine. 2015; 40(3): 18492.

3. Adams J, Peng W, Cramer H, Sundberg T, Moore C, Amorin-Woods L, et al. The prevalence, patterns, and predictors of chiropractic use among US adults. Spine. 2017; 42(23): 1810-6.

4. Groeneweg R, Assen L, Kropman H, Leopold H, Mulder J, Smits EBC, et al. Manual therapy compared with physical therapy in patients with non-specific neck pain: a randomized controlled trial. Chiropr \& Manual Ther. 2017; 25(1): 1-12.

5. Fejer R, Kyvik KO, Hartvigsen J. The prevalence of neck pain in the world population: a systematic critical review of the literature. Eur Spine J. 2006; 15(6): 834-48.

6. Cohen SP, Hooten WM. Advances in the diagnosis and management of neck pain. BMJ. 2017; 358: j3221.

7. Cohen SP. Epidemiology, diagnosis, and treatment of neck pain. Mayo Clin Proc. 2015; 90(2): 284-99.

8. López I, Sollano VE, Corral T. Reduction of cervical and respiratory muscle strength in patients with chronic nonspecific neck pain and having moderate to severe disability. Disabil Rehabil. 2018; 40(21): 2495-504.

9. Martel J, Dugas C, Lafond D, Descarreaux M. Validation of the French version of the bournemouth questionnaire. J Can Chiropr Assoc. 2009; 53(2): 10210.

10. Deyo RA, Battie M, Beurskens A, Bombardier C, Croft P, Koes B, et al. Outcome measures for low back pain research: a proposal for standardized use. Spine. 1998; 23(18): 2003-13.

11. Parks K, Crichton K, Goldford R, McGill S. A comparison of lumbar range of motion and functional ability scores in patients with low back pain: assessment for range of motion validity. Spine. 2003; 28(4): 380-4.

12. Kose G, Hepguler S, Atamaz F, Oder G. A comparison of four disability scales for Turkish patients with neck pain. J Rehabil Med. 2007; 39(5): 358-62.
13. Bicer A, Yazici A, Camdeviren H, Erdogan C. Assessment of pain and disability in patients with chronic neck pain: reliability and construct validity of the Turkish version of the neck pain and disability scale. Disabil Rehabil. 2004; 26(16): 959-62.

14. Telci EA, Karaduman A, Yakut Y, Aras B, Simsek IE, Yagli N. The cultural adaptation, reliability, and validity of neck disability index in patients with neck pain: a Turkish version study. Spine. 2009; 34(16): 1732-5.

15. Jordan A, Manniche C, Mosdal C, Hindsberger C. The copenhagen neck functional disability scale: a study of reliability and validity. J Manipulative Physiol Ther. 1998; 21(8): 520-7.

16. Jordan A, Bendix T, Nielsen H, Hansen FR, Høst D, Winkel A. Intensive training, physiotherapy, or manipulation for patients with chronic neck pain: a prospective, single-blinded, randomized clinical trial. Spine. 1998; 23(3): 311-8.

17. Bolton JE, Humphreys BK. The bournemouth questionnaire: a short-form comprehensive outcome measure. II. Psychometric properties in neck pain patients. J Manipulative Physiol Ther. 2002; 25(3): 141-8.

18. Bolton JE, Breen AC. The bournemouth questionnaire: a short-form comprehensive outcome measure. I. Psychometric properties in back pain patients. J Manipulative Physiol Ther. 1999; 22(8): 503-10.

19. Yılmaz O, Gafuroğlu Ü, Yüksel S. Translation, reliability, and validity of the Turkish version of the neck bournemouth questionnaire. Turk J Phys Med Rehabil. 2019; 65(1): 59-66.

20. Kaergaard A, Andersen JH, Rasmussen K, Mikkelsen $\mathrm{S}$. Identification of neck-shoulder disorders in a 1 year follow-up study. Validation of a questionnaire-based method. Pain. 2000; 86(3): 305-10.

21. Berg A, Suhonen R, Idvall E. A survey of orthopaedic patients' assessment of care using the individualised care scale. J Orthop Nurs. 2007; 11(3-4): 185-93.

22. Arslan S, Şener DK, Cangür Ş. Pediatri hemşireliği ögrencileri klinik rahatlık ve endișe değerlendirme aracının geçerlik ve güvenirliği. DÜ Sağlık Bil Enst Derg. 2018; 8(2): 61-6.

23. Vernon H, Mior S. The neck disability index: a study of reliability and validity. J Manipulative Physiol Ther. 1991; 14(7): 409-15.

24. Wheeler AH, Goolkasian P, Baird AC, Darden BV. Development of the neck pain and disability scale: item analysis, face, and criterion-related validity. Spine. 1999; 24(13): 1290.

25. Pinar R. Reliability and construct validity of the SF36 in Turkish cancer patients. Qual Life Res. 2005; 14(1): 259-64.

26. Ware Jr, John E, Sherbourne CD. The mos 36-item short-form health survey (sf-36): I. Conceptual framework and item selection. Med Care. 1992; 30(6): 473-83.

27. Korkmaz S, Goksuluk D, Zararsiz G. MVN: An r package for assessing multivariate normality.R J. 2014; 6(2): 151-62.

28. Zinbarg RE, Revelle W, Yovel I, Li W. Cronbach's $\alpha$, Revelle's $\beta$, and McDonald's $\omega \mathrm{H}$ : Their relations 
with each other and two alternative conceptualizations of reliability. Psychometrika. 2005; 70(1): 123-33.

29. Zinbarg RE, Yovel I, Revelle W, McDonald RP. Estimating generalizability to a latent variable common to all of a scale's indicators: A comparison of estimators for $\omega \mathrm{h}$. Appl Psychol Meas. 2006; 30(2): 121-44.

30. Andresen EM. Criteria for assessing the tools of disability outcomes research. Arch Phys Med Rehabil. 2000; 81: 15-20.

31. Marx RG, Menezes A, Horovitz L, Jones EC, Warren RF. A comparison of two time intervals for test-retest reliability of health status instruments. J Clin Epidemiol. 2003; 56(8): 730-5.

32. Terwee CB, Bot SD, Boer MR, Windt DA, Knol DL, Dekker J, et al. Quality criteria were proposed for measurement properties of health status questionnaires. J Clin Epidemiol. 2007; 60(1): 34-42.

33. McHorney CA, Tarlov AR. Individual-patient monitoring in clinical practice: are available health status surveys adequate? Qual Life Res. 1995; 4(4): 293-30.

34. Feise RJ, Menke JM. Functional rating index: a new valid and reliable instrument to measure the magnitude of clinical change in spinal conditions. Spine. 2001; 26(1): 78-87.

35. Hyland ME. A brief guide to the selection of quality of life instrument. Health Qual Life Outcomes. 2003; 1(1): 24.

36. Hair JF, Black Wc, Babin Bj, Anderson Re. Multivariate data analysis. 7th ed. New York: Pearson; 2010.

37. Soklic M, Peterson C, Humphreys BK. Translation and validation of the German version of the Bournemouth questionnaire for neck pain. Chiropr \& Manual Ther. 2012; 20(1): 2.

38. World Health Organization. The international classification of functioning, disability and health (ICF). Geneva: WHO; 2001.

39. Geri T, Signori A, Gianola S, Rossettini G, Grenat G, Checchia G, et al. Cross-cultural adaptation and validation of the neck bournemouth questionnaire in the Italian population. Qual Life Res. 2015; 24(3): 735-45.

40. Hogg JS, Velde G, Carroll LJ, Holm LW, Cassidy JD, Guzman J, et al. The burden and determinants of neck pain in the general population: results of the bone and joint decade 2000-2010 task force on neck pain and its associated disorders. J Manipulative Physiol Ther. 2009; 32(2): 46-60.

41. Terwee CB, Schellingerhout JM, Verhagen AP, Koes BW, Vet HC. Methodological quality of studies on the measurement properties of neck pain and disability questionnaires: a systematic review. J Manipulative Physiol Ther. 2011; 34(4): 261-72.

42. Allen MJ, Yen WM. Introduction to measurement theory. Long Grove: Waveland Press; 2002.

43. Ghasemi F, Yoosefinejad AK, Pirouzi S, Ghaem H. Evaluating the cross-cultural adaptation, reliability, and validity of the Persian versions of the copenhagen neck function disability scale and neck bournemouth questionnaire. Spine. 2019; 44(2): E126-32. 